\title{
Food security effects of smallholders' participation in apple and mango value chains in north-western Ethiopia
}

\author{
Mengistie Mossie ${ }^{1,2^{*}} \mathbb{0}$, Alemseged Gerezgiher ${ }^{1}$, Zemen Ayalew ${ }^{2}$ and Asres Elias ${ }^{3}$
}

\begin{abstract}
Background: While it has identified that linking smallholders in the agri-food value chain remains to be a promising strategy to get out of the poverty trap in many developing countries, less is known about the food security implications of smallholders' participation in the fruits value chain. This paper examines the effects of apple and mango smallholder farmers' participation along the value chain, focusing on their household food security in north-western Ethiopia.

Methods: Primary data for the study were obtained from a random sample of 384 households, 211 of which are fruit value chain participants, and the remainder are non-participants. The study used the propensity score matching (PSM) method to establish a causal relationship between the participation of the fruit value chain and changes in household food security.

Results and conclusions: Results indicate that participation in the apple and mango value chain has a robust and positive effect on the food security of smallholders as measured by household food consumption in kilocalorie. The unconfoundedness and overlapping assumptions were fulfilled by applying the nearest neighbor and kernel-based matching algorithms. The study confirms that the more apple and mango farmers join the value chain, the higher their household food intake becomes. Support for fruit farmers is, therefore, a promising policy approach that can help improve household food security in rural Ethiopia.
\end{abstract}

Keywords: Household food security, Fruits value chain, Smallholder farmer, Propensity score matching, Ethiopia

\section{Background}

Food security has been a top priority and a global concern for decades [1]. Among several definitions of food security, the most widely used definition is that "food security exists when all people have physical, social and economic access to adequate, safe and nutritious food at all times to meet their dietary needs and food preferences for an active and healthy life" [2]. In the first place, the definition focuses on the daily consumption of food,

*Correspondence: mengistiemossie@gmail.com

${ }^{1}$ Center for Rural Development Studies, Addis Ababa University, P.O. Box 1176, Addis Ababa, Ethiopia

Full list of author information is available at the end of the article where distribution systems ensure food's continued availability. Second, the concept of access to adequate and safe food includes the continued physical availability of food, and thirdly, the continued economic capacity to acquire food through the supply system. In developing countries, household food security is determined by what households can produce, storing, preparing, and purchasing from the market [3]. Correspondingly, food insecurity refers to "a situation in which people have no secure access to adequate amounts of safe and nutritious food for normal growth and development and for an active and healthy life" [4]. While some progress has been made in the fight against hunger in developing countries through increased food production, many people 
still have food insecurity and some form of malnutrition [5]. Sub-Saharan Africa's (SSA) widely experienced food security challenge is mainly attributed to the poor performance of its agricultural sector [6].

One of the most likely pathways towards improving rural households' livelihoods and food security is integrating them into lucrative agricultural markets [7]. Participation in viable markets demands system thinking to overcome barriers that limit smallholders' participation in international and local markets $[8,9]$. Of particular interest are agricultural value chains that link producers with traders and consumers of agricultural products [10]. In agriculture, the value chain is simply described as a market-oriented approach that encompasses the entire range of activities that are undertaken to bring a product to end-users passing through the various stages of production, processing, distribution, and marketing [11]. In SSA, agricultural value chains are currently undergoing a rapid transformation driven by urbanization, dietary changes, technological changes, rising incomes, and expansion of food markets, among other underlying trends [12]. This increasing dynamism and transformation of agri-food systems offer farmers the opportunity to produce and sell high-value products, translating their vertically coordinated relationships into premium prices and letting them capture a bigger share of the price paid by final consumers [13]. There is evidence in Ethiopia, as is elsewhere in SSA, increased access and participation of smallholders in cash-crop markets (e.g., fruits) present opportunities to improve their productivity, income, and food security [14].

Ethiopia has abundant agricultural resources and diverse environmental conditions to produce temperate, tropical, and sub-tropical fruit crops [15]. Common temperate fruit crops such as apples, plums, peaches, and pears can be grown in the highlands, where cold temperatures prevail, while tropical, and sub-tropical fruits produced at low-to-medium altitudes, such as bananas, citrus, mango, avocado, and others $[16,17]$. In the local economy, fruit production in Ethiopia plays a crucial role as a livelihood source for about six million farmers. In the 2018/2019 cropping season, $114,421.81$ hectares were occupied under the production of fruits, while a total of $7,924,306.92$ quintals of fruit have produced locally [18]. North-western Ethiopia, particularly the Upper-Blue Nile Basin, is agro-ecologically suitable and known for its production potential of different types of fruits. In the basin context, fruit crops gradually transform from subsistence to cash crops (such as mango and apple) for smallholder growers $[19,20]$.

Mango (Mangifera indica) is known as the "king of the fruits" [21], which makes the crop valued for food security, particularly for developing countries such as
Ethiopia, where the realization of food security is still a problem. In Ethiopia, mango production increased from 70,000 metric tons in $2013 / 2014$ to 105,000 metric tons in $2017 / 2018$ by $45 \%$ [22]. Kent, Keitt, Tommy Atkins, and Apple mango are among the main cultivars grown [23]. In the midland and lowland areas of the UpperBlue Nile Basin, mango-an an evergreen fruit crop is the leading fruit produced by smallholder farmers [20]. Apple (Malus domestica) is among the pome deciduous fruits. In addition to its dietary importance, apple trees in the Ethiopian highlands can improve soil conservation. It is an exogenous crop expanded through government and non-government institutions' support, and private growers, including farmers [24]. In their home compound in Chencha town, southern Ethiopia, British missionaries first introduced apple seedlings to be planted. In 2017, the production of apple fruit in Chencha was about 154 tons per year [25]. There is, however, no actual information on the current national level of apple crop yield in Ethiopia. Apple production has been expanded in the Upper-Blue Nile Basin, especially in several Awi-Zone highland areas, where it is serving as the main cash crop for smallholders in supplementing their livelihoods [24].

Apples and mangoes were selected as the two most important crops to be considered for the purpose of this study due to the fact that they are high-value cashcommodities and are mainly produced in the Upper-Blue Nile Basin. Moreover, these fruits have a high potential for the contribution of poverty reduction, income generation, and the attainment of household food security. Despite the rising importance of these fruits in the Ethiopian economy, there is insufficient empirical evidence of the effect of these fruits on many aspects of food security [26]. Most of the reviewed documented empirical studies such as Getahun et al. [27], Mengesha et al. [28], Gebre, Rik and Kijne [29], and Tarekegn et al. [30] concentrate mostly on southern and central parts of Ethiopia, and therefore the contextual relevance to north-western Ethiopia may be scarce. That means, results from these studies vary depending on the product being considered, the number and organization of available channels, and the institutional, technical, social, and economic environment the farmers operate in. Furthermore, many related studies conducted in different parts of Ethiopia such as Tamirat and Muluken [25], Getahun et al. [27], Honja et al. [31], and Rahiel et al. [32] did not pay due attention to analyzing the food security effect; rather they focused mainly on identifying production potentials and constraints, marketing channels, and distribution of margins. Despite their significant contributions to the livelihood of millions of people in the Upper-Blue Nile Basin, Ethiopia, fruit crops have not been given research attention. Therefore, this study envisages examining the effects 
of participation in the fruit value chain on smallholder farmers' food security in the Upper-Blue Nile Basin, Ethiopia, focusing on mango and apple crops.

\section{Methods}

\section{Description of the study area}

This study was conducted in the Dibatie district from the Metekel Zone, the Fagita Lekoma and Banja districts from the Awi-Zone, and Bahir Dar Zuria district from the West Gojjam Zone, four districts in the Upper-Blue Nile Basin, Ethiopia (Fig. 1). The livelihood of the communities in these districts mainly comprised a rain-fed mixed subsistence crop production-livestock farming system. Fruit crops such as apple and mango are also the most important contributors to agricultural activity and, hence, a focus for the development in the north-western highlands of Ethiopia. The basin has a high potential for fruit farming and, generally, it is considered among the important fruit-growing corridors in the country $[19,20]$. A brief description of the selected districts is presented in Table 1.

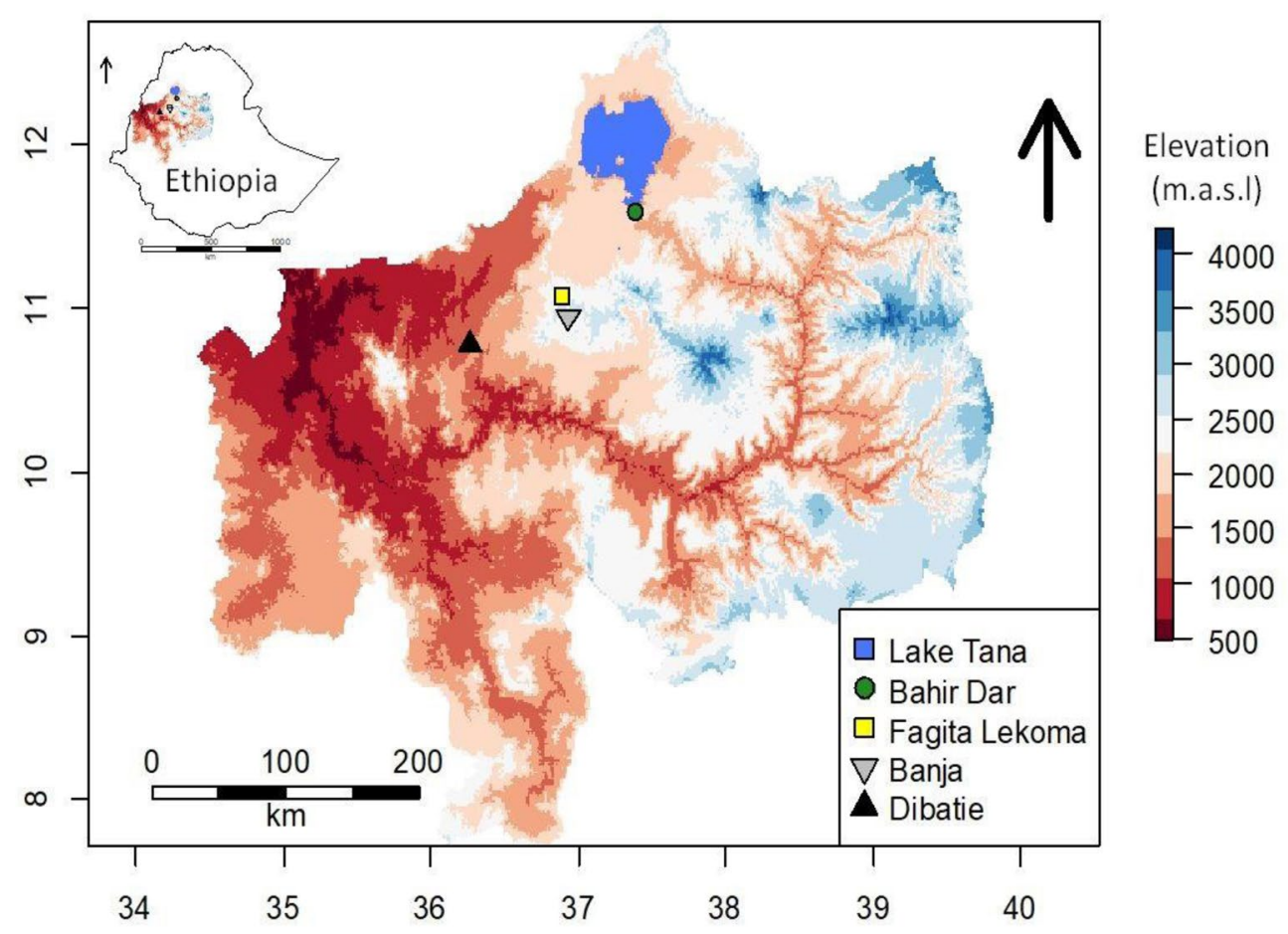

Fig. 1 Location map of the study districts

Table 1 Description of the study districts

\begin{tabular}{lllll}
\hline Features (unit) & \multicolumn{2}{l}{ Study districts } & & Dibatie \\
\cline { 2 - 5 } & Banja & Fagita Lekoma & Bahir Dar Zuria & $1479-1709$ \\
\hline Altitude (m a.s.l.) & $1850-2925$ & $1800-2900$ & $1922-2250$ & $25-32$ \\
Temperature ( $\left.{ }^{\circ} \mathrm{C}\right)$ & $9-26$ & $9-25$ & $15-28$ & $850-1200$ \\
Annual rainfall (mm) & $1958-3465$ & $1951-3424$ & $895-2037$ & Tropical hot humid \\
Agro-ecological zone & Moist subtropical & Moist subtropical & Humid subtropical & Nitosols and Vertisols \\
Soil type & Acrisols and Nitosols & Nitosols and Acrisols & Leptosols and Nitosols & Maize and millet \\
Dominant staple crops & Teff and barley & Barley and teff & Millet, teff, wheat, and maize & Cattle, goats, and donkeys \\
Dominant livestock & Cattle, horses, and sheep & Cattle, horses, and sheep & Cattle, goats, sheep, and donkeys & Mango, coffee, and groundnut \\
Dominant cash crops & Potatoes, garlic, and apple & Potatoes, garlic, and apple & Khat, mango, avocado, papaya, and & coffee
\end{tabular}




\section{Sampling procedure}

The sample households were selected by utilizing a multistage random sampling procedure. In the first stage, four districts (Banja and Fagita Lekoma from the appleproducing districts; and Dibatie and Bahir Dar Zuria from the mango-producing districts) were purposively selected. These districts were chosen in such a way that they are capable of capturing the variations between the agro-climate zones, the socio-economic conditions, and their fruit production experiences. In the second stage, 10 kebeles (i.e., the smallest administrative unit below the district) were randomly selected (Table 2). A list of rural households was compiled from the respective kebele agricultural offices as a sampling frame with the help of community informants and then stratified them into participants and non-participants in the fruit value chain.

In this study, fruit value chain participants defined as those who used to sell a part of her/his apple and mango produce in the market during the 2019/2020 production year. Non-participant households are defined as farmers who have not used to sell a part of her/his apple and mango produce within the same period while they are located in the same kebele.

Using the Mugenda and Mugenda [33] table, the sample size was determined by considering the confidence level, the degree of variability, and the level of precision. Consequently, $n$ was calculated as follows:

$$
n=\frac{Z^{2} p(1-p)}{d^{2}} \quad n=\frac{(1.96)^{2}(0.5)(0.5)}{(0.05)^{2}}=384,
$$

where $n$ is the required sample size when the population is greater than 10,000 ; $Z$ is the standard normal deviation (1.96) corresponding to $95 \%$ confidence level; $p$ is the predicted target population characteristic assumed by the researcher (is equal to 0.5 where the occurrence level is not known); and $d^{2}$ is the desired level precision (0.05).

A sample (n) of 384 fruit-growing households was then set on. Finally, among the selected kebeles, 161 apple producers and 223 mango producers were proportionally allocated.

\section{Data collection}

Both quantitative and qualitative data were collected through face-to-face interviews as well as Focused Group Discussions (FGDs) from primary and secondary sources. The survey was carried out from November 2019 to January 2020 by trained data collectors. Study participants (i.e., household heads) in four districts were interviewed using a structured survey questionnaire. The questionnaire was translated into Amharic, the local language, and then pre-tested on a random sample of 35 non-sample households prior to the actual survey. It was then designed to provide information on a wide range of items, including household and farm characteristics, access to institutional and infrastructure services, ownership of assets (crop and livestock) and household food consumption. Due to the lack of panel data on the fruit subsector in Ethiopia, this study used a cross-sectional research design that may not fully account for endogeneity biases. However, researchers have made efforts, such as quality data collection and close supervision, to minimize the problem.

\section{Data analysis}

This study used descriptive and inferential statistics, and an econometric model to analyze data. Descriptive statistics, such as percentage, frequency, mean, and standard deviation were used to present summary statistics of quantitative data pertaining to socio-demographic,

Table 2 Household distribution and sample intensity across the study kebeles

\begin{tabular}{lllrr}
\hline Study district & Selected kebeles & $\begin{array}{l}\text { No. of fruit producers in each } \\
\text { kebele }\end{array}$ & Sample size (number) & Percent \\
\hline Dibatie & Dibatie 01 & 505 & 24 & 6.25 \\
& Gallessa & 820 & 39 & 10.15 \\
& Dibatie 02 & 420 & 20 & 5.21 \\
Bahir Dar Zuria & Laguna & 696 & 60 & 15.62 \\
& Wonjeta & 928 & 80 & 20.83 \\
Fagita Lekoma & Gafera & 316 & 26 & 6.77 \\
Banja & Endewuha & 560 & 46 & 11.98 \\
& Bata & 263 & 21 & 5.46 \\
Total & Basanguna & 188 & 15 & 3.91 \\
\hline
\end{tabular}

Source: own computation from each kebele administration data (2019/2020) 
economic, and institutional characteristics of sample households. Inferential statistics, such as t-test and Chisquare $\left(x^{2}\right)$ test, were used to assess the existence of statistically significant differences in observations between fruits value chain participant and non-participant groups of respondents. For the econometric analysis, the propensity score matching (PSM) procedure was used to examine the food security effects of farmers' participation in the fruits value chain. The analysis employed different matching algorithms using the psmatch 2 command implemented on STATA 14.0 platform. In what follows, the results pertaining to estimation of propensity scores, average treatment effect on the treated (ATT), and matching quality analyses are presented.

Estimating the effect of treatment on outcomes is a major challenge because of the following three expected biases: (1) the selection of observables resulting from sampling bias, (2) the selection of a comparison group in the presence of externalities, (3) selection of unobservable resulting from differences between the treated and the control groups in the distribution of their unobserved characteristics [34]. In simple regression or logistic models, the coefficients on the control variables would be the same for participants and non-participants. Due to this limitation, in the literature, most of the studies used the PSM model to examine the effect of treatment on outcomes [35, 36]. Because of its non-parametric approach to the balance of covariates between the treated and the control groups, the PSM method improves the ability of regression to produce reliable causal estimates [37]. Despite many advantages, PSM cannot handle the third problem listed above (i.e., unobserved characteristics), and therefore depends on the quality of the observational data [38]. This study attempted to minimize this limitation by collecting quality data, the inclusion of the most relevant variables, and the use of recommended matching techniques. According to Dehejia and Wahba [39], the PSM model can be specified as:

$$
p(X)=\operatorname{Pr}\left(D_{i}=1 \mid X\right)=E\left(D_{i} \mid \mathrm{X}\right),
$$

where $D i=(0,1)$ is the dummy for value chain participation, and $X$ represents the vector of household characteristics. The conditional distribution of $X$, given the propensity score $p(X)$, is similar in both groups of fruits value chain participants and non-participants.

In practice, a model (Logit or Probit for binary treatment) is estimated in which participation in a treatment is explained by several pre-treatment characteristics and then predictions of this estimation are used to create the propensity score that ranges from 0 to $1[36,40]$. Although both models provide almost similar output, this study used the Logit model to estimate the propensity score. In estimating the logit model, the dependent variable was participation in the fruits value chain, which takes the value of 1 if a household is a participant and 0 otherwise. According to Rosenbaum and Rubin [36], the logit model can be specified as:

$$
\mathrm{P}_{i}=\frac{e^{z i}}{1+e^{Z i}},
$$

where $P_{i}$ is the probability of participation.

$$
Z_{i}=a_{0}+\sum_{(i=1)}^{n} a_{i} X_{i}+U_{i},
$$

where $i=1,2,3, \ldots, n a_{0}=$ intercept, $a_{i}=$ regression coefficients to be estimated, $U_{i}=$ a disturbance term, and $X_{i}=$ pre-intervention characteristics.

The probability that a household belongs to non-participant is:

$$
1-\mathrm{P}_{i}=\frac{1}{1+e^{Z i}} .
$$

The odds ratio is $=\frac{P_{i}}{1-p_{i}}=e^{Z_{i}}$.

Taking the natural logarithm, then $Z_{i}$

$$
=a_{0}+\sum_{i=1}^{n} a_{i} X_{i}+U_{i}
$$

The validity of the outputs of the PSM method depends on the satisfaction of two basic assumptions: the Conditional Independence Assumption (CIA) and the Common Support Condition (CSC) [41]. CIA (also known as Unconfoundedness Assumption) argues that treatment needs to meet the criterion of being exogenous, suggesting that any systematic difference in outcomes between treatment and control groups with the same values for characteristics $X$ can be attributed to treatment. The common support or overlap condition means that there is sufficient overlap in the treated and untreated units' characteristics to find appropriate matches (or common support). After estimating the propensity scores, the ATT can then be estimated as:

$$
\begin{aligned}
A T T & =E\left(Y_{1 i}-Y_{2 i} \mid D_{i}=1\right) \\
& =E\left[E\left(Y_{1 i}-Y_{2 i} \mid D_{i}=1, P(X)\right)\right] \\
& =E\left[E\left(Y_{1 i} \mid D_{i}=1, P(X)\right)-E\left(Y_{2 i} \mid D_{i}=0, P(X)\right)\right]
\end{aligned}
$$

where $Y_{1 i}$ is the expected calorie intake if the household $i$ participates in the fruits value chain; $Y_{2 i}$ is the expected calorie intake of household $i$ if it chooses not to participate in the fruits value chain; $D_{i}=(0,1)$ is the dummy for value chain participation, and $X$ represents the vector of household characteristics. 
The propensity score is a continuous variable, and there is no way to get participants with the same score as its counterfactual(s). Thus, estimation of the propensity score is insufficient to compute the average treatment effect given by Eq. (8) Thus, after estimation of the propensity scores, seeking an appropriate matching estimator is the major task. There are different matching estimators in theory, including nearest neighbor matching (NNM), kernel-based matching (KBM), radius matching, stratification and interval matching [41]. All matching estimators contrast the outcome of a treated individual with outcomes of comparison group members. PSM estimators differ not only in how the neighborhood for each treated individual is defined, and the common support problem is handled, but also concerning the weights assigned to these neighbors. According to Caliendo and Kopeinig [41], the most widely used matching algorithms are the NNM and KBM. Therefore, this study used the NNM and KBM matching estimators. Discussion of the differences between these matching techniques and how each work are addressed in Rosenbaum and Rubin [36].

\section{Measuring food security}

Selecting an appropriate food security indicator is the most challenging issue due to the complexity of the food security concept [42]. This is because none of the indicators capture the concept of food security accurately. Therefore, the present study used one of the indicators mentioned in Lele et al. [43] which grouped indicators into eight different categories based on the underlying data source. Each of these could be used in various ways. The indicators based on sources of data are individual or household recall, national observations, market observations, prevalence and depth of undernourishment, anthropometric measures, breastfeeding and sanitation, clinical data, composite indexes, and multidimensional measures. Among the indicators mentioned above, individual or household recall indicators are considered the easiest way to obtain relevant data from households using survey questionnaires.

The number of total calories per household intake for each food item is one of the most important household food security measures [44]. In this study, the distinction in calorie intake between the treated and the control group was estimated. Interviewees were requested to report foodstuffs consumed, in-kind and quantity, bought or otherwise by their households in the last seven days preceding the survey. In converting the amount of physical food consumed by the family into calories consumed adjusted for household sex and age, we accompanied the following steps. First, local measurement units were converted into a common unit of measurement for each food item consumed. Second, each food item consumed was converted to calories using the national food composition table compiled by the Ethiopian Health and Nutrition Research Institute [45]. Third, all food calories consumed were then added to and converted into daily amounts. The total food calories were altered in an adult equivalent (AE) unit per family using Storck et al. [46] conversion factor for adult equivalent. The resulting average kilocalorie ( $\mathrm{kcal}$ ) per adult household equivalent per day was compared with the established threshold (minimum subsistence kcal requirement) set by FDRE [47] as $2100 \mathrm{kcal}$ for Ethiopia. This study, therefore, uses $2100 \mathrm{kcal}$ as an exact cut-off point to dichotomize the household as food secure and food insecure. Finally, the household whose physical food consumption in kcal is greater than or equal to $2100 \mathrm{kcal} /$ day/AE was categorized as food secure, whereas less than $2100 \mathrm{kcal} /$ day $/ \mathrm{AE}$ was categorized as food insecure.

\section{Results and discussion}

\section{Characteristics of the surveyed respondents}

Results related to demographic, socio-economic and farm characteristics of the respondents are presented in Table 3. The study reveals that about $48.45 \%$ and $59.64 \%$ of apple and mango households, respectively, participated in the fruit value chain. This shows that participants and non-participants are systematically different. The treatment group exhibits higher food consumption than the control group by a factor of 788.53 and 1225.89 kilocalories for apple and mango households, respectively. Taking into account the nationally established food insecurity threshold (i.e., $2100 \mathrm{cal}$ of food per adult equivalent per day), 47.82 and $34.97 \%$ of apple and mango households were found to be food insecure.

Regarding the demographic characteristics, the result shows that almost equal proportions of male-headed households were in the participants and non-participant categories of apple farmers. Mango value chain participants $(39.09 \%)$ were headed by males as compared to $32.33 \%$ for non-participants. Participants in both apple and mango value chains were about two and one years younger than non-participants, respectively. In terms of education level, there was a significant variation across respondents' education levels. Value chain participants had about three years more education than non-participants for both apple and mango. The results highlighted that mean labor (in man equivalent) was significantly greater for apple value chain participants than non-participants. However, there is no statistically significant difference between participant and non-participant mango growers. In terms of fruit farming experience, non-participants, on average, have less experience than the participating households. 
Table 3 Description and summary statistics of the surveyed respondents

\begin{tabular}{|c|c|c|c|c|c|c|}
\hline \multirow[t]{2}{*}{ Variable } & \multicolumn{3}{|c|}{ Apple producers $(n=161)$} & \multicolumn{3}{|c|}{ Mango producers $(n=223$ ) } \\
\hline & Participants (78) & $\begin{array}{l}\text { Non- } \\
\text { participants } \\
(83)\end{array}$ & t-test $\left(X^{2}\right.$ test $)$ & Participants (133) & $\begin{array}{l}\text { Non- } \\
\text { participants } \\
(90)\end{array}$ & t-test ( $\mathrm{X}^{2}$ test) \\
\hline \multicolumn{7}{|l|}{ Outcome variable } \\
\hline Household food intake (kcal) & 2868.32 & 2079.79 & $-788.53^{* *}$ & 4096.31 & 2870.42 & $-1225.89^{* *}$ \\
\hline \multicolumn{7}{|l|}{ Household characteristics } \\
\hline $\begin{array}{l}\text { Sex of the household head; male ( } 1=\text { male; } \\
0=\text { female) }\end{array}$ & 39.80 & 39.10 & 0.91 & 52.00 & 29.10 & $7.89^{* * *}$ \\
\hline Average age of the head (years) & 48.80 & 50.50 & $-4.49^{* * *}$ & 46.00 & 47.00 & -0.89 \\
\hline $\begin{array}{l}\text { Average educational level of the head (years } \\
\text { of schooling) }\end{array}$ & 4.46 & 1.25 & $3.21^{* * *}$ & 4.18 & 0.70 & $-3.48^{* * *}$ \\
\hline Average working labor (man equivalent) & 4.53 & 3.41 & $-1.12^{* * *}$ & 3.56 & 3.77 & 0.21 \\
\hline Fruit farming experience (years) & 9.10 & 7.10 & $-4.67^{* * *}$ & 13.00 & 6.30 & $-6.89^{* * *}$ \\
\hline Per capita income (ETB) & 36858.17 & 30221.20 & -6636.97 & $59,837.48$ & $42,416.09$ & $-17421.39^{*}$ \\
\hline \multicolumn{7}{|l|}{ Farm characteristics } \\
\hline $\begin{array}{l}\text { Incidence of disease and insects; yes ( } 1=\text { yes; } \\
\quad 0=\text { no) }\end{array}$ & 9.90 & 24.20 & $12.53^{* * *}$ & 12.60 & 28.30 & $53.24^{* * *}$ \\
\hline Average livestock size (TLU) & 4.90 & 5.98 & $3.04^{* *}$ & 6.20 & 5.70 & -0.72 \\
\hline \multicolumn{7}{|l|}{ Institutional support variables } \\
\hline $\begin{array}{l}\text { Access to price information; yes }(1=\text { yes; } \\
0=\text { no) }\end{array}$ & 36.00 & 16.10 & $29.84^{* * *}$ & 42.20 & 7.20 & $60.09^{* * *}$ \\
\hline $\begin{array}{l}\text { Average frequency of extension contacts per } \\
\text { year (no. of days) }\end{array}$ & 10.90 & 3.70 & $-6.64^{* * *}$ & 6.00 & 2.50 & $-4.06^{* * *}$ \\
\hline \multicolumn{7}{|l|}{ Transaction costs variable } \\
\hline $\begin{array}{l}\text { Average distance to the nearest market } \\
\text { (minutes of walking) }\end{array}$ & 37.60 & 41.50 & $3.99^{*}$ & 33.10 & 46.20 & $13.14^{* * *}$ \\
\hline
\end{tabular}

** and * represent $1 \%, 5 \%$ and $10 \%$ level of significance, respectively

ETB (Ethiopian Birr) is the Ethiopian currency, and during the survey period 1 USD was about 29 ETB

Source: own survey data $(2019 / 2020)$

Regarding household per capita income, the study reveals that, on average, respondents who participated in apple and mango value chains were received more annual income than non-participants. The results also reveal that diseases and insect pests were higher in nonparticipants' apple and mango farms than participants. About $34.10 \%$ and $40.90 \%$ of the respondents observed disease and insect pest problems in their apple and mango orchard, respectively. In terms of livestock assets measured in tropical livestock unit (TLU), non-participants in the apple value chain were better-off than participant households. On the contrary, mango value chain participants had more livestock than non-participants. Our result further depicts that, on average, about 46.15 and $31.73 \%$ of apple and mango participants in the value chain had access to price information, compared to 19.39 and $8.00 \%$ of the non-participants, respectively. Participants in the apple value chain had a more significant number of average extension contacts (10.90 days/year) than non-participants (3.70 days/year). Likewise, mango value chain participants had a more significant number of extension contacts (6.00 days/year) relative to nonparticipants ( 2.50 days/year).

\section{Apple and mango value chain actors (mapping) in the study areas}

Figure 2 (a) and (b) presents apple and mango value chain players in the study districts from input suppliers to a final purchaser of the products. Initially, input suppliers could supply inputs to apple and mango producers in the value chain segments. The study showed that currently, non-governmental organizations such as Agri-service Ethiopia, the district office of agriculture, and private seedling suppliers are the primary input supply sources. Smallholder producers are the second major actors who grow and market apples and mangoes. According to the study, $87 \%$ of the apple respondents sold their produce on the farm field through collectors, while $32 \%$ of mango producers sold their produce on the nearest local market roadsides. The rest were sold in Enjibara, Chagini, and Bahir Dar towns. 

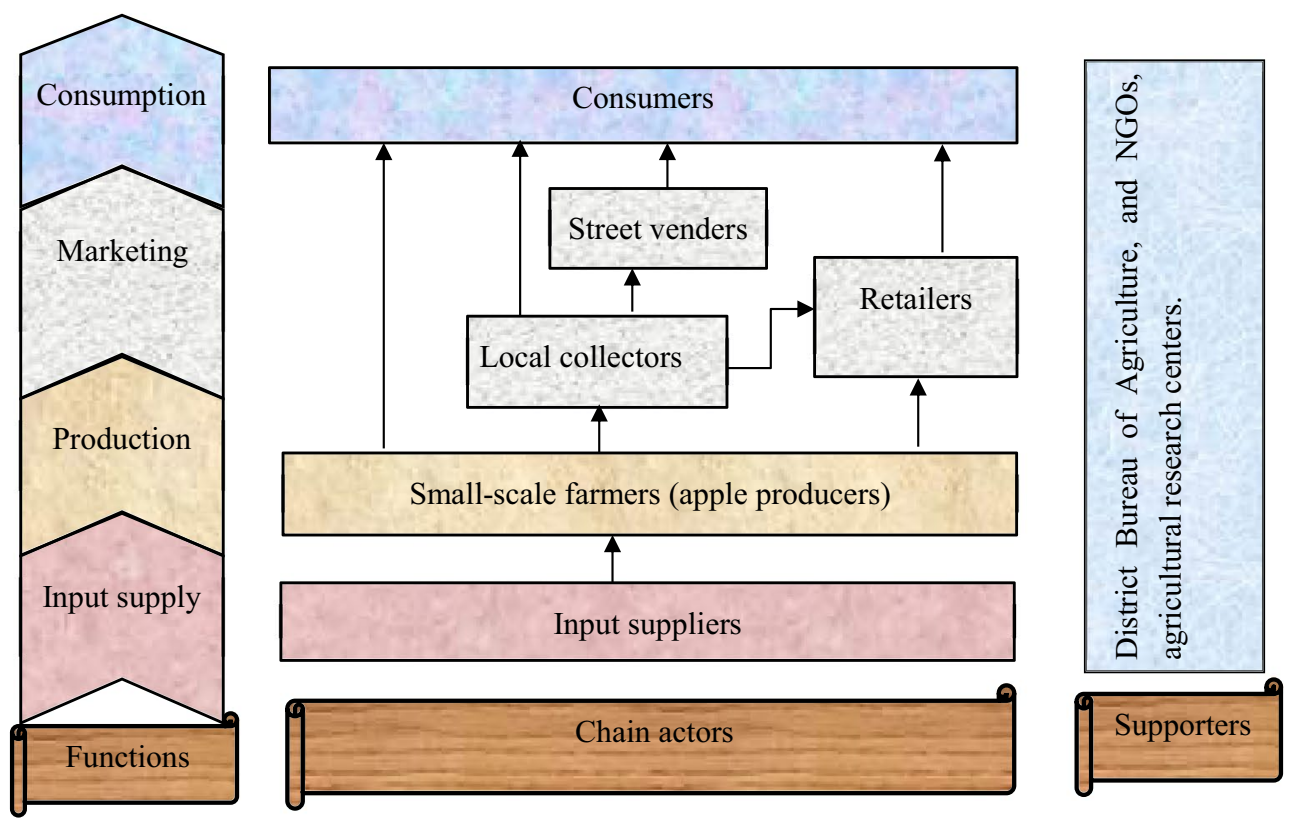

(a) Apple value chain map of actors
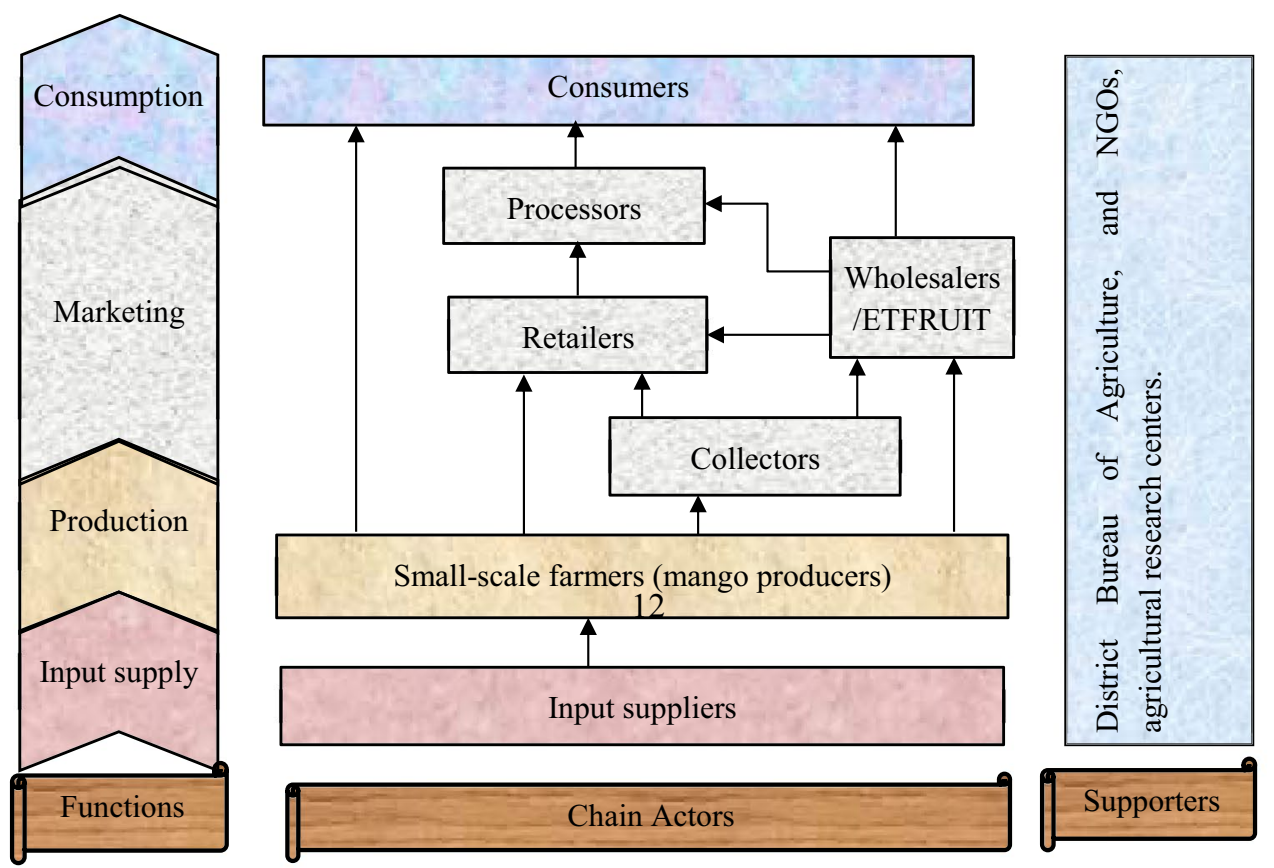

(b) Mango value chain map of actors

Fig. 2 Apple and mango value chain map of actors in the districts. Source: own sketch based on field data, 2019/2020

The information obtained from the focused group discussions (FGD) conducted revealed that there were some steps in the mango sale process. "First, a rural collector was told by farmers to buy his produce. A collector came back for arrangements to look for and agree with a retailer and vendors. The buyer then goes on to check the quality and negotiate the price. There was usual mischief (cheat in weighing) this time". Smallholder producers also 
clarified their argument that "aside from low prices, up to $25 \%$ of product volume was cheated. The selling had to be made as soon as harvested, as the products are perishable. For collection and product distribution, farmers used wooden boxes and baskets (local containers made up of bamboo trees). No scientific measurement, rather amount (pricing of a basket), accompanied the price discovery. The basket's estimated average weight was approximately $25 \mathrm{~kg}$, and the wooden box was nearly $50 \mathrm{~kg}$ for both apple and mango". Survey farmers also pointed out that "no set of agreements to make the marketing focused on the contract is available for both fruits". There was no technology for farmers to build a pricing advantage over time.

Local collectors, on the other hand, are market players who have either resided in rural kebeles or towns such as Chagini, Enjibara, or Bahir Dar. In the study area, collectors collect products from producers in the village markets and from farms to resell them to retailers or wholesalers. They bought fruits from farms and did not involve brokers. Some of them are opportunistic to be interested throughout the remaining months in many other businesses or farming. In the Enjibara area, apple collectors sell to street vendors and sell to Zengena Lake visitors. On the other side, the retailers coordinate 'collectors' groups to gather mangoes at the farmers and then load them into vehicles that directly leave for marketing. They primarily used animal packs and small trucks to transport the products. Wholesalers are traders who purchase large quantities of mango from collectors and farm gates and resell them to other traders. Purchasing, repacking by mango size are specific practices conducted by wholesalers along the mango value chain. They sell to consumers as well. They have improved storage, transportation, and communication links than most, compared to other traders. ETFRUIT is the major wholesaler in Ethiopia.

Retailers can purchase products from producers, collectors, and wholesalers (only for mango) directly. Mango retailers primarily purchase from wholesalers and sell to consumers, while apple retailers buy from collectors. Retailers sell apples and mango and also sell other fruits such as bananas and oranges. Their sales points are at markets in the city, in the village centers, and along roadsides. The retail stands were bad, made of plastic and wood, mostly used for sunlight protection. Sewerage was lacking, not convenient for displaying products, vulnerable to rain and intense sunlight, and exposed to pollution. Also, retailers who cause problems in the process of buying and selling due to the presence of a small space between various store stands were poorly defined in the retail area. In addition, there were no organized institutions to improve their situation. The buyers from retailers were final consumers (households, restaurants, and hotels). The processing is limited to juice extraction, where cafes or juice houses take the initiative in preparation.

Consumers are the final buyer of the products. In the study areas, it would be possible to classify two sets of consumers: private users and institutions. Private consumers are workers, urban and rural residents who buy and consume apples and mango. Universities/colleges, hospitals, etc., are among the institutions. Private consumers usually buy apples and mango from producers, retailers, and wholesalers. Consumers use their quality requirements for purchasing fruit, such as color, form, smell, weight, size, etc. During the fasting time, intake is significantly higher.

Support service providers are several institutions in the research areas that support the fruit value chain. Together with the district's Bureau of Agriculture, the standard service providers are NGOs (e.g., Japan International Cooperation Agency/JICA, and Agri-service Ethiopia), and agricultural research centers. They provide technical assistance/training for the preparation of seedbeds, the application of fertilizer, crop protection, and post-harvest management. They seek mutual help in delivering programs. However, there is no elevated platform where all of them may meet regularly to discuss existing tasks and procedures at each stage of the value chain. The information obtained from the FGD demonstrates that the extension service for agricultural practices is accessible to the growers even though it is not sufficient to develop the fruit farmers' technical knowledge.

\section{Description of agronomic and value-addition techniques adopted}

Table 4 shows some of the major agronomic and valueaddition techniques adopted by apple and mango growers in the respective study districts. Regarding cropping systems practiced, the information obtained from the respondents shows that apple and mango trees are planted haphazardly without proper spacing and intercropped with other crops such as coffee, maize, and groundnut, khat, root crops, and legumes, and vegetable crops. There is no cost that is directly associated with mango production because the crop husbandry practices such as land preparation, weeding, and pruning are indirectly done during the cultivation of other targeted annual crops. In all study districts, more than $50 \%$ of respondents support the intercropping of their apple and mango with other crops. This result is supported by Dapaah et al. [48], who revealed that intercropping as compared to monocropping is a common practice applied worldwide as it improves the use of land efficiently, minimizes crop failure risks, reduces 
Table 4 Agronomic and value-addition activities adopted among the study districts

\begin{tabular}{|c|c|c|c|c|c|c|}
\hline \multirow[t]{2}{*}{ Items (\%) } & \multicolumn{6}{|c|}{ Districts } \\
\hline & Banja & Fagita Lekoma & Bahir Dar Zuria & Dibatie & Total & Chi-Sq. $\left(x^{2}\right)$ test \\
\hline \multicolumn{7}{|l|}{ (1) Cropping systems practiced } \\
\hline Monocropping & 27.00 & 33.31 & 6.44 & 15.70 & 20.61 & \multirow[t]{2}{*}{$4.2^{* * *}$} \\
\hline Intercropping & 73.00 & 66.69 & 93.56 & 84.30 & 79.39 & \\
\hline \multicolumn{7}{|c|}{ (2) Disease and insect pest management techniques used } \\
\hline Weeding and hoeing & 7.90 & 14.60 & 2.93 & 3.64 & 7.27 & \multirow[t]{7}{*}{$36.0^{* *}$} \\
\hline Removing dead trees/cutting & 0.00 & 4.22 & 2.16 & 1.20 & 1.89 & \\
\hline Spraying pesticide chemicals & 1.11 & 2.80 & 5.00 & 2.43 & 2.84 & \\
\hline Intercropping & 13.93 & 12.62 & 14.30 & 12.00 & 13.21 & \\
\hline Cultural methods & 5.61 & 5.54 & 6.44 & 4.84 & 5.61 & \\
\hline All of the above methods applied & 4.04 & 6.90 & 16.41 & 7.22 & 8.64 & \\
\hline No controlling method used & 67.41 & 53.32 & 52.76 & 68.67 & 60.54 & \\
\hline \multicolumn{7}{|l|}{ (3) Value-addition activities applied } \\
\hline Cleaning & 12.44 & 29.20 & 34.32 & 55.40 & 32.84 & \multirow[t]{4}{*}{$39.2^{* * *}$} \\
\hline Sorting & 56.20 & 31.90 & 32.10 & 39.80 & 40 & \\
\hline Packing & 2.26 & 1.46 & 5.00 & 3.60 & 3.08 & \\
\hline No value-addition practiced & 29.10 & 37.44 & 28.58 & 1.20 & 24.08 & \\
\hline \multicolumn{7}{|l|}{ (4) Irrigation practice } \\
\hline Practice irrigation & 94.45 & 97.20 & 91.42 & 19.36 & 79.61 & \multirow[t]{2}{*}{$22.8^{* *}$} \\
\hline No irrigation & 5.55 & 2.80 & 8.58 & 80.64 & 20.39 & \\
\hline
\end{tabular}

****** and * represent $1 \%, 5 \%$ and $10 \%$ level of significance, respectively

Source: own survey data $(2019 / 2020)$

soil erosion, and increases yield stability. As described in Sect. 3.1, about $34.10 \%$ and $40.90 \%$ of the respondents observed disease and insect pest problems in their apple and mango orchard, respectively. However, the majority of the respondents $(60.54 \%)$ not used any controlling method in their production. However, only $2.84 \%$ of the total respondents sprayed pesticide chemicals.

Results of field observation by researchers show that anthracnose and powdery mildew as the two most common and widespread fungal diseases of mango in the study areas. Diseases such as apple scab, powdery mildew, and twig blight are the major ones that contributed to the reduction of apple production and productivity. Likewise, aphid, scale borer, and caterpillar are the major insect pests affecting apple production. Value-addition as a core component of value chain study results from activities such as cleaning, sorting/grading, packaging, storing, transporting, and processing. In developing countries, low agro-industrial expansion has mainly been the major cause of stagnation for the value-addition of market-oriented crops (Punjabi, 2007). In this study, sorting, cleaning, and packing are reported to be the major adopted value-addition practices. Note, however, that a significant number $(24.08 \%)$ of both apple and mango growers supplied their products to the market without any value-addition activities (Table 4). Results of this study further indicate that almost more than $90 \%$ of respondents irrigate their apple farms from both applegrowing districts. The variation is, however, recorded from mango growing districts. This means that less than half of respondents in Dibatie did not practice in their mango farm, while the majority (91.4\%) of respondents used irrigation in Bahir Dar Zuria.

\section{Econometric model estimation results Estimation results of propensity score}

Table 5 shows the estimation results of the logit regression model. The model is statistically significant as shown in the lower part of Table 5. The estimated model appears to perform well for our intended matching exercise. The pseudo- $R^{2}$ value is 0.18 and 0.16 for the respective crops. A low $R^{2}$ value means that participant households do not have many distinct characteristics overall and as such finding a good match between the participant and non-participant households becomes easier. After matching, there should be no systematic differences in the distribution of covariates between both groups and therefore, the pseudo$R^{2}$ should be fairly low [40]. Since we are interested in computing the propensity scores, which are used in the matching process, later on, we are not going into the details of why and how each of the covariates affected 
Table 5 Results of the logistic regression model

\begin{tabular}{|c|c|c|c|c|c|c|}
\hline \multirow[t]{2}{*}{ Variables } & \multicolumn{3}{|c|}{ Apple producers $(n=161)$} & \multicolumn{3}{|c|}{ Mango producers $(n=223)$} \\
\hline & Coefficient & Std. Err & $Z$-value & Coefficient & Std. Err & $Z$-value \\
\hline Sex of the household head & -0.567 & 0.512 & -1.11 & 0.0408 & 0.423 & 0.10 \\
\hline Age of the household & 0.0367 & 0.0194 & 1.89 & -0.00768 & 0.0145 & -0.53 \\
\hline Educational level & $0.144^{* *}$ & 0.0657 & 2.97 & $0.124^{* *}$ & 0.0631 & 2.50 \\
\hline Working labor force & $0.310^{*}$ & 0.155 & 1.99 & $0.231^{*}$ & 0.150 & 1.78 \\
\hline Fruit farming experience & 0.0814 & 0.0560 & 1.45 & $0.0786^{* *}$ & 0.0283 & 2.77 \\
\hline Per capita income & -0.0132 & 0.0287 & -0.46 & 0.0182 & 0.0194 & 0.94 \\
\hline Disease and insect pests & $-0.319^{* *}$ & 0.429 & -2.74 & $-0.898^{* *}$ & 0.346 & -2.59 \\
\hline Livestock size & -0.0407 & 0.0901 & -0.45 & 0.0597 & 0.0429 & 1.39 \\
\hline Access to price information & $1.427^{* * *}$ & 0.410 & 3.48 & $0.997^{* *}$ & 0.378 & 2.64 \\
\hline Extension contacts & 0.0342 & 0.0294 & 1.16 & -0.0434 & 0.0301 & -1.44 \\
\hline Distance to the nearest market & -0.00298 & 0.0140 & -0.21 & -0.0184 & 0.0110 & -1.67 \\
\hline Constant & $-3.960^{* *}$ & 1.358 & -1.36 & 0.323 & 1.168 & 0.28 \\
\hline Number of observations & 161 & & & 223 & & \\
\hline Pseudo- $R^{2}$ & 0.18 & & & 0.16 & & \\
\hline Likelihood ratio (LR) X² (12) & 62.35 & & & 80.84 & & \\
\hline Prob $x^{2}$ & 0.000 & & & 0.000 & & \\
\hline Log likelihood & -80.346 & & & -109.979 & & \\
\hline
\end{tabular}

${ }^{*},{ }^{* *},{ }^{* * *}$ represent statistical significance at $10 \%, 5 \%$, and $1 \%$ level, respectively

Source: own survey data (2019/2020)

households' participation in the apple and mango value chain. Looking into the estimated coefficients, the result shows the existence of a statistically significant difference between treated $(n=211)$ and control $(n=173)$ groups regarding the distributions of education, working labor force, farming experience, disease, and insect pests, and access to price information. These variables were responsible for households' differential participation in apple and mango value chains.

Our finding pertaining to the effect of education on participation in the apple and mango value chain is related to that of Slamet, Nakayasu and Ichikawa [49] in Indonesia. However, our finding is contrasted with Ouma et al. [50], who reported that banana farmers' education level negatively affects their market participation in Burundi and Rwanda. Availability of the working labor force in the household exhibits a significant and positive relationship with participation in the value chain. Likewise, the farming experience is also positively associated with fruit growers' probability to participate in value chains $[19,20]$. In a recent study in Ethiopia, Gebru et al. [14] revealed that perceived production risks such as disease and insect pests discouraged households from engaging in the fruit and vegetable business. On the other hand, our finding is related to Magesa, Michael and Ko [51], who revealed that farm households who have access to better price information are likely to access the agrifood market.

\section{Matching quality analysis}

The quality of the matching process was checked after estimating the propensity scores for both the participant and non-participant groups. Figure 3 (a) and (b) shows the histograms of the estimated propensity scores for both participants and non-participants in the apple and mango value chains. Visual inspection of the density distributions of the estimated propensity scores shows that the common support condition was satisfied, as there was substantial overlap in the distribution of both the participant and non-participant propensity scores for both apple and mango. The upper half of the graph displays the distribution of propensity scores for participants and the bottom half refers to non-participants. The score densities are on the y-axis. The predicted output lies purely between 0 and 1 and is a reliable indicator of this. It shows, therefore, that there is adequate overlap in the distribution of the estimated likelihood of participation.

Table 6 presents the results of matching quality from pre-and post-matching covariate balancing tests. The result shows that the assumption of balancing property is satisfied. After performing the two matching algorithms (nearest neighbor and kernel) the balancing property test was performed. The mean differences for the predictor variables were significantly smaller after matching when compared to before matching. The mean standard biases after matching were reduced to below $5 \%$ for the respective crops. The $p$-value of the probability ratio tests 


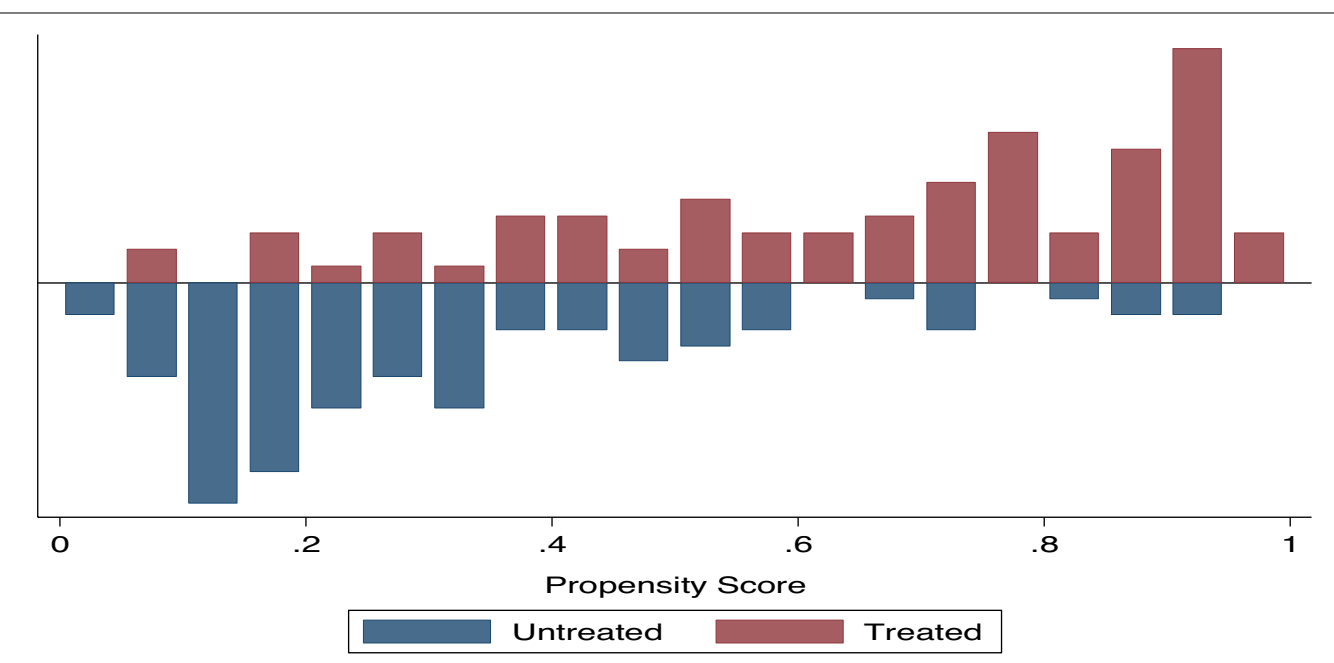

(a) Apple value chain participation

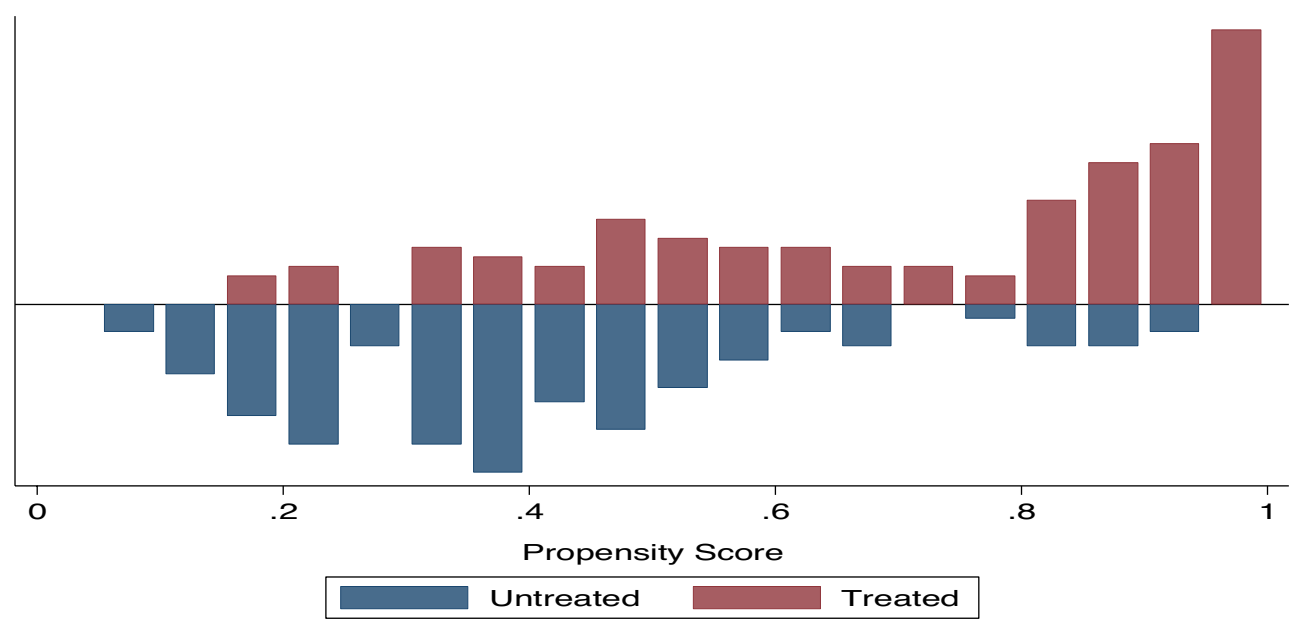

(b) Mango value chain participation

Fig. 3 Distribution of propensity score and common support for estimate of propensity score. Source: own survey data (2019/2020)

Table 6 Matching quality tests

\begin{tabular}{llclc}
\hline Fruit type & Test for & Before matching & After matching \\
\cline { 3 - 4 } & & & $\begin{array}{l}\text { Nearest neighbor matching } \\
\text { (NNM) }\end{array}$ & $\begin{array}{l}\text { Kernel-based } \\
\text { matching (KBM) }\end{array}$ \\
\hline Apple producers & & 0.285 & 0.03 & 0.023 \\
& Pseudo- $R^{2}$ & 78.63 & 5.50 & 4.64 \\
Mango producers & $L R x^{2}(p$-value) & 20.18 & 4.3 & 3.6 \\
& Standardized bias (mean) & 0.268 & 0.04 & 0.07 \\
& Pseudo- $R^{2}$ & 80.57 & 5.23 & 4.38 \\
& $L R x^{2}(p$-value) & 18.45 & 4.25 & 4.07 \\
\hline
\end{tabular}

Source: own survey data (2019/2020) 
after matching exhibits that the predictor variables are not significantly different between both the treated and the control groups. This is the best quality indicator for fulfilling the assumption of conditional independence by the PSM [36]. Pseudo- $R^{2}$ also declined significantly after matching. Low pseudo- $\mathrm{R}^{2}$, low mean standardized bias, high overall bias reduction, and insignificant p-values of the probability ratio test support the assumption that both groups have the same distribution in covariates $x$ after matching. These results suggest that the proposed propensity score specification is reasonably successful in balancing the distribution of covariates between the two groups and can be used to assess the effect of value chain participation among groups of households with similar observed characteristics.

Estimation of average treatment effect on the treated (ATT) The estimation results of the ATT are obtained for household food calorie intake using the matching algorithms (Table 7). Table 7 provides estimates of the average effect estimated by nearest neighbor matching (NNM) and kernel-based matching (KBM) approaches. Both matching methods were used to check the robustness of the results. In the case of NNM, the calorie intake of the apple participants was $2889.04 \mathrm{kcal}$ and that of the non-participants was $2103.86 \mathrm{kcal}$, while the calorie intake of the mango participants was $3096.31 \mathrm{kcal}$ and that of the non-participants was $2778.64 \mathrm{kcal}$. Using KBM (0.01 bandwidth), apple participants consumed $2868.32 \mathrm{kcal}$ per adult equivalent per day, which is approximately $7.03 \%$ higher than the corresponding non-participants. Using a bandwidth of 0.01 , the calorie intake (mean food consumption) was about $3042.33 \mathrm{kcal}$ for mango participants, while the corresponding figure for non-participants was $2870.41 \mathrm{kcal}$. This shows that the participants were $7.67 \%$ better than non-participants in terms of household food calorie intake. Both matching algorithm estimates were significant at the $1 \%$ level.
Overall, the ATT result indicates that the participation of the apple and mango value chain has a positive and significant effect on the food security of the study areas of farm households. This result is supported by the fact that growers belonging to the value chain have earned relatively higher prices for their products $[12,13]$. The result is consistent with previous studies that indicate a positive association between value chain participation and rising levels of farm household food security. In their analysis in Tanzania, Mmbando, Wale and Baiyegunhi [52] revealed that participation in the marketing of maize and pigeon pea increased the proportion of consumption spending by $19.8 \%$ and $28.9 \%$, respectively.

\section{Conclusion and recommendations}

This study analyzed food security effects of apple and mango value chain participation in north-western Ethiopia using recent data from a cross-section of smallholders, measured by household food consumption in kilocalorie. With this, we contribute to the emerging fruits value chain literature since most of the reviewed documented empirical studies have shown the role of agricultural commercialization (e.g., fruits) on smallholders in terms of productivity and income effects.

Comparisons of average household food intake between participants and non-participants in the apple and mango value chain have revealed some significant differences. However, it is not possible to attribute the difference in household food consumption (calorie intake) of the participants and non-participants exclusively to the fruits value chain as comparisons are not yet restricted to respondents who have similar characteristics. Hence, further exploration was performed employing the propensity score matching (PSM) model to address the issue. The fitted values from the logistic regression generated propensity scores that were used to match the participants and non-participants of the apple and mango value chain. The unconfoundedness and overlapping assumptions were fulfilled by applying

Table 7 Results of average treatment effect on the treated

\begin{tabular}{|c|c|c|c|c|}
\hline \multirow{2}{*}{$\begin{array}{l}\text { Outcome } \\
\text { variableOutcome } \\
\text { variable } \\
\text { Weekly calorie intake }\end{array}$} & \multirow[t]{2}{*}{ Matching algorithm } & \multicolumn{3}{|c|}{ Mean outcome variable based on matched observation } \\
\hline & & Participants & Non-participants & Difference (ATT) \\
\hline \multirow[t]{2}{*}{ Apple producer } & NNM with replacement & 2889.04 & 2103.86 & $(785.18)^{* * *}$ \\
\hline & KBM (bwidth 0.01) & 2868.32 & 2679.78 & $(188.54)^{* * *}$ \\
\hline \multirow[t]{2}{*}{ Mango producer } & NNM with replacement & 3096.31 & 2778.64 & $(317.67)^{* * *}$ \\
\hline & KBM (bwidth 0.01) & 3042.33 & 2870.41 & $(171.92)^{* * *}$ \\
\hline
\end{tabular}

$p<0.001$; NNM, nearest neighbor matching; KMB, kernel-based matching

Source: own survey data $(2019 / 2020)$ 
the nearest neighbor and kernel-based matching algorithms. More particularly, the gain in household food calorie intake is higher for households with a larger educational level and households accessed to price information.

The empirical results from this study confirm the more apple and mango households are involved in the fruit value chain, the better the household food intake and food security become. Suggesting that participation in the apple and mango value chain has significantly increased participating households' calorie intake in the study districts. Given the significant contributions of farmers' participation in the apple and mango value chains to household food security, policymakers in Ethiopia should encourage more households to participate in the fruit value chain. For example, awareness creation to other non-participant farmers can be considered as one of the best options for improving households to participate in the fruits value chain. Policies aimed at providing education to farmers and improving access to price information could enhance the ability of households to participate in the fruits value chain and thus improve their food security. In addition, appropriate policy interventions that encourage institutional support from different stakeholders, such as research institutions, could strengthen the participation of small-scale farmers in the fruit value chain.

Although the estimation technique used in this study was based on a rigorous statistical procedure, it used cross-sectional data and, hence, there are potentials for improvement through further study. The first aspect in this regard calls for the collection of panel data from more farm households. Further research using different value chain actors (e.g., fruit traders' participation along the value chain) should also get attention.

\begin{abstract}
Acknowledgements
The authors would like to extend their sincere gratitude to the Addis Ababa University and Japan International Cooperation Agency (JICA) for funding this research. Dr. Zerihun Nigussie, Professor Nigussie Haregeweyn, Dr. Daregot Berihun, and Dr. Derege Tsegaye areespecially grateful. Our thanks also go to all data collectors and survey respondents. The authors recognize and thank Mr. Anteneh Wubet and Mr. Nigus Tadesse, the field research assistants of the SATREPS project, for their assistance in collecting data. Lastly, the authors would like to extend their deepest thanks to the editor and three anonymous reviewers for constructive comments and suggestions on an earlier version of this manuscript.
\end{abstract}

\footnotetext{
Authors' contributions

Authors contributed to this work as follows: MM (conceptualization, questionnaire development, project administration, methodology, investigation, data curation, fund acquisition, software, formal analyses, original-draft writing, visualization, writing-review and editing, validation), AG (supervision, project administration, resources, validation, data curation, editing), ZA (supervision, software, data curation, writing-review and editing, validation), AE (supervision, data curation, fund acquisition, writing-review and editing, validation). All authors read and approved the final manuscript.
}

Funding

This study was supported by a research grant from the Addis Ababa University and the Japan International Cooperation Agency (JICA) project (Grant Number JPMJSA1601).

\section{Availability of the data and materials}

It is possible to request the data from the corresponding author.

\section{Declarations}

\section{Ethics approval and consent to participate}

An official letter was written by the Center for Rural Development, Addis Ababa University, with a detailed description of the objective and role of the study. The purpose of this research was clarified for each participant and a consent form was attached to each questionnaire during the interview process. Finally, the respondents guaranteed that their privacy would be protected by a strict anonymity standard.

\section{Consent for publication}

All authors agree and consent for the manuscript to be published.

\section{Competing interests}

The authors declare that they have no competing interests.

\section{Author details}

${ }^{1}$ Center for Rural Development Studies, Addis Ababa University, P.O. Box 1176, Addis Ababa, Ethiopia. ${ }^{2}$ College of Agriculture and Environmental Sciences, Bahir Dar University, P.O. Box 79, Bahir Dar, Ethiopia. ${ }^{3}$ Faculty of Agriculture, Tottori University, 4-101 Koyama-Minami, Tottori 680-8550, Japan.

Received: 4 September 2020 Accepted: 15 May 2021

Published online: 18 October 2021

\section{References}

1. Conceição P, Levine S, Lipton M, Warren-Rodríguez A. Toward a food secure future: ensuring food security for sustainable human development in Sub-Saharan Africa. Food Policy. 2016;60:1-9. https://doi.org/10. 1016/j.foodpol.2016.02.003.

2. Ecker $\mathrm{O}$, Breisinger $\mathrm{C}$. The food security system: a new conceptual framework. International Food Policy Research Institute (IFPRI) Discussion Paper 01166). 2012. https://ebrary.ifpri.org/cdm/ref/collection/p15738coll2/id/ 126837.

3. Bickel G, Nord M, Price C, Hamilton W, Cook J. Guide to measuring household food security. USDA, Food and Nutrition Service; 2000 (cited 2009 Oct 6). http://www.fns.usda.gov/FSEC/FILES/FSGuide.pdf.

4. Maxwell D, Caldwell R, Langworthy M. Measuring food insecurity: Can an indicator based on localized coping behaviors be used to compare across contexts? Food Policy. 2008;33(6):533-40. https://doi.org/10. 1016/j.foodpol.2008.02.004.

5. Sibhatu KT, Krishna W, Qaim M. Production diversity and dietary diversity in smallholder farm households. Proc Natl Acad Sci. 2015;112(34):10657-62.

6. Boliko MC. FAO and the situation of food security and nutrition in the world. J Nutr Sci Vitaminol. 2019;65:S4-8.

7. Orr A, Donovan J, Stoian D. Smallholder value chains as complex adaptive systems: a conceptual framework. J Agribusiness Dev Emerg Econ. 2018;8(1):14-33. https://doi.org/10.1108/JADEE-03-2017-0031.

8. Tschirley D, Reardon T, Dolislager M, Snyder J. The rise of a middle class in East and Southern Africa: implications for food system transformation. J Int Dev. 2015;27(5):628-46.

9. Lundy M, Becx G, Zamierowski N, Amrein A, Hurtado Bermúdez JJ, Mosquera Echeverry EE, Rodríguez F. LINK methodology: A participatory guide to business models that link smallholders to markets. Version 2.0. Cali, Centro Internacional de Agricultura Tropical (CIAT). 2012.

10. Lie H. Inclusive value chain development: applying systems thinking and participatory modeling to dairy value chain analyses in Nicaragua and Tanzania. 2017. 
11. Devaux A, Maximo T, Jason D, Douglas H. Agricultural innovation and inclusive value-chain development: a review. J Agribusiness Dev Emerg Econ. 2018;8(1):99-123. https://doi.org/10.1108/JADEE-06-2017-0065.

12. Reardon T. The hidden middle: the quiet revolution in the midstream of agrifood value chains in developing countries. Oxf Rev Econ Policy. 2015;31(1):45-63. https://doi.org/10.1093/oxrep/grv011.

13. Wiggins S. African agricultural development: Lessons and challenges. J Agric Econ. 2014;65(3):529-56. https://doi.org/10.1111/1477-9552.12075.

14. Gebru KM, Leung M, Rammelt C, Zoomers A, van Westen G. Vegetable business and smallholders' food security: empirical findings from Northern Ethiopia. Sustainability. 2019;11(3):1-28. https://doi.org/10.3390/ su11030743.

15. Worako TK. Transactions costs and spatial integration of vegetable and fruit market in Ethiopia. Ethiopian J Econ. 2015;24(1):89-130.

16. Gebre Mariam S. Status of commercial fruit production in Ethiopia. Ethiopian Agricultural Research Organization; 2003. http://hdl.handle.net/ $123456789 / 2114$

17. Joosten F. Exporting fruit and vegetables from Ethiopia: Assessment of development potentials and investment options in the export-oriented fruit and vegetable sector. Addis Ababa; 2011.

18. CSA. Agricultural sample survey: Area and production of major crops. Central Statistical Agency of Ethiopia. Addis Ababa, Ethiopia; 2019.

19. Nigussie Z, Tsunekawa A, Haregeweyn N, Adgo E, Nohmi M, Tsubo M, Aklog D, Meshesha DT, Abele S. Farmers' perception about soil erosion in Ethiopia. Land Degrad Dev. 2017;28(2):401-11. https://doi.org/10.1002/ Idr.2647.

20. Mossie M, Gerezgiher A, Ayalew Z, Nigussie Z. Determinants of smallscale farmers' participation in Ethiopian fruit sector's value chain. Cogent Food Agric. 2020;6(1):1842132. https://doi.org/10.1080/23311932.2020. 1842132.

21. Ullah H, Ahmad S, Thompson AK, Ahmad W, Nawaz MA. Storage of ripe mango (Mangifera indica L.) CV. Alphonso in controlled atmosphere with elevated $\mathrm{CO}_{2}$. Pak J Bot. 2010;42(3):2077-84.

22. Fita T. White mango scale, aulacaspis tubercularis, distribution and severity status in east and west Wollega Zones, Western Ethiopia. Sci Technol Arts Res J. 2014;3(3):1-10. https://doi.org/10.4314/star.v3i3.1.

23. Bekele M, Satheesh N, Jemal S. Screening of Ethiopian mango cultivars for suitability for preparing jam and determination of pectin, sugar, and acid effects on physico-chemical and sensory properties of mango jam. Sci African. 2020;7:e00277. https://doi.org/10.1016/j.sciaf.2020.e00277.

24. Fetena S, Lemma B. Assessment on major apple diseases and insect pests in Chench and BonkeWoredas of Gamo-Gofa zone, Southern Ethiopia. Scholarly J Agric Sci. 2014. 4(7):394-402. http://www.scholarly-journals. com/SJAS.

25. Tamirat G, Muluken P. Analysis of apple fruit value chain in southern Ethiopia; the Case of Chencha District. Greener J Plant Breeding Crop Sci. 2018:6(3):26-34. https://doi.org/10.15580/GJPBCS.2018.3.100218043.

26. Wiersinga R, de Jager A. Business opportunities in the Ethiopian fruit and vegetable sector. Ministry of Agriculture. Nature and Food Quality; 2009. https://edepot.wur.nl/12.

27. Getahun W, Agajie T, Tadele M, Setotaw F. Apple value chain analysis in the Central Highlands of Ethiopia. Int J Agric Innov Res. 2018;7(1):2319-1473.

28. Mengesha S, Abate D, Adamu C, Zewde A, Addis Y. Value chain analysis of fruits: the case of mango and avocado producing smallholder farmers in Gurage Zone, Ethiopia. J Dev Agric Econ. 2019;11(5):102-9. https://doi. org/10.5897/JDAE2018.1038.

29. Gebre GG, Rik E, Kijne A. Analysis of banana value chain in Ethiopia: approaches to sustainable value chain development. Cogent Food \& Agriculture. 2020;6(1):1742516. https://doi.org/10.1080/23311932.2020. 1742516.

30. Tarekegn K, Asado A, Gafaro T, Shitaye Y. Value chain analysis of banana in Bench Maji and Sheka Zones of Southern Ethiopia. Cogent Food Agric. 2020;6(1):1785103. https://doi.org/10.1080/23311932.2020.1785103.

31. Honja T, Geta E, Mitiku A. Mango value chain analysis: The Case of Boloso Bombe Woreda, Wolaita Zone, Southern Ethiopia. 2014;4(25):230-240. http://www.iiste.org/.

32. Rahiel HA, Zenebe KA, Leake WG, Gebremedhin WB. Assessment of production potential and post-harvest losses of fruits and vegetables in northern region of Ethiopia. Agric Food Security. 2018;7(29):1-13. https:// doi.org/10.1186/s40066-018-0181-5.

33. Mugenda OM, Mugenda AG. Quantitative and qualitative approaches. Nairobi: Acts Press; 2003.

34. Wooldridge JM. Econometric analysis of cross section and panel data. Cambridge: MIT press; 2010

35. Smale M, Diakité L, Keita N. Millet transactions in market fairs, millet diversity and farmer welfare in Mail. Environ Dev Econ. 2012;17(5):523-46.

36. Rosenbaum PR, Rubin DB. The central role of the propensity score in observational studies for causal effects. Biometrika. 1983;70(1):41-55. https://doi.org/10.1093/biomet/70.1.41.

37. Conniffe D, Gash V, Connell PJ. Evaluating state programmes: "natural experiments" and propensity scores. Econ Social Rev. 2000;31(4):283-308. https://hdl.handle.net/2262/62595.

38. Li M. Using the propensity score method to estimate causal effects: a review and practical guide. Organizational Res Methods. 2013;16(2):188226. https://doi.org/10.1177/1094428112447816.

39. Dehejia $\mathrm{RH}$, Wahba S. Propensity score-matching methods for nonexperimental causal studies. Review of Economics and statistics. 2002;84(1):151-161. https://EconPapers.repec.org/RePEc:tpr:restat:v:84:y: 2002:i:1:p:151-161.

40. Aku A, Mshenga P, Afari-Sefa V, Ochieng J. Effect of market access provided by farmer organizations on smallholder vegetable farmer's income in Tanzania. Cogent Food Agric. 2018;4(1):1560596. https://doi.org/10. 1080/23311932.2018.1560596.

41. Caliendo M, Kopeinig S. Some practical guidance for the implementation of propensity score matching. J Econ Surveys. 2008;22(1):31-72. https:// doi.org/10.1111/j.1487-6419.2007.00527.x.

42. Hendriks SL. The challenges facing empirical estimation of household food (in) security in South Africa. Dev South Afr. 2005;22(1):103-23. https://doi.org/10.1080/03768350500044651.

43. Lele U, Masters WA, Kinabo J, Meenakshi J, Ramaswami B, Tagwireyi J, Goswami S. Measuring food and nutrition security: An independent technical assessment and user's guide for existing indicators. Rome: Food Security Information Network, Measuring Food and Nutrition Security Technical Working Group, 2016. 177. http://www.fsincop.net/topics/fns-measu rement.

44. Berry EM, Dernini S, Burlingame B, Meybeck A, Conforti P. Food security and sustainability: can one exist without the other? Public health nutrition. 2015. 18(13):2293-2302. https://https://doi.org/10.1017/S136898001 $500021 X$.

45. EHNRI. Food composition table for use in Ethiopia. Ethiopian Health and Nutrition Research Institute. Addis Ababa; 1998.

46. Storck H, Adenew B, Emana B, Begander R, Hailu G. Management strategies for farming systems in an uncertain environment and approaches for their improvement. 1997

47. FDRE (The Federal Democratic Republic of Ethiopia). Food Security Strategy. In Paper Prepared for the Consultative Group Meeting of December 10-12, 1996. Addis Ababa, Ethiopia.

48. Dapaah H, Asafu-Agyei J, Ennin S, Yamoah C. Yield stability of cassava, maize, soya bean and cowpea intercrops. J Agric Sci. 2003;140(1):73.

49. Slamet AS, Nakayasu A, Ichikawa M. Small-scale vegetable farmers' participation in modern retail market channels in Indonesia: the determinants of and effects on their income. Agriculture. 2017;7(2):11.

50. Ouma E, Jagwe J, Obare GA, Abele S. Determinants of smallholder farmers' participation in banana markets in Central Africa: the role of transaction costs. Agric Econ. 2010;41(2):111-22.

51. Magesa MM, Michael K, Ko J. Access and use of agricultural market information by smallholder farmers: measuring informational capabilities. Electronic J Inform Syst Dev Countries. 2020;86(6):12134. https://doi.org/ 10.1002/isd2.12134.

52. Mmbando FE, Wale EZ, Baiyegunhi LJ. Welfare impacts of smallholder farmers' participation in maize and pigeonpea markets in Tanzania. Food Security. 2015;7(6):1211-24. https://doi.org/10.1007/s12571-015-0519-9.

\section{Publisher's Note}

Springer Nature remains neutral with regard to jurisdictional claims in published maps and institutional affiliations. 